\title{
SABERES INDÍGENAS SOBRE OS CÉUS: ASTRONOMIA CULTURAL EM DOCUMENTOS EDUCACIONAIS BRASILEIROS
}

\section{Indigenous knowledge about the skies: cultural astronomy in Brazilian educational documents}

\author{
Márdila Alves Bueno ${ }^{1}$ \\ Elrismar Auxiliadora Gomes Oliveira ${ }^{2}$ \\ Marta de Souza Rodrigues ${ }^{3}$ \\ Eulina Maria Leite Nogueira ${ }^{4}$
}

Resumo: O objetivo deste trabalho ${ }^{5}$ é analisar o espaço ocupado por saberes sobre os céus indígenas em documentos educacionais nacionais e do estado do Amazonas. A metodologia tem abordagem qualitativa e os documentos selecionados para análise foram: Parâmetros Curriculares Nacionais, Base Nacional Comum Curricular, Propostas Curriculares do Estado do Amazonas e Referencial Curricular Nacional para as Escolas Indígenas. Para análise desses documentos utilizamos a Análise de Conteúdo. Os resultados mostram que, dos documentos analisados, somente o Referencial Curricular Nacional para as Escolas Indígenas, documento específico para essas culturas, apresenta explicitamente elementos a respeito dos saberes sobre os céus indígenas. Nos outros documentos, a abordagem específica de saberes indígenas sobre os céus é pouco recorrente. Em se tratando das Propostas Curriculares do Estado do Amazonas, a falta desses temas é preocupante. No estado com o maior número de pessoas autodeclaradas indígenas no país, a abordagem de temas relacionados aos saberes sobre os céus indígenas ressaltaria a importância da valorização dos conhecimentos produzidos por esses povos. A falta dessa abordagem pode contribuir para naturalizar um currículo que apresenta predominantemente a cultura dominante. A pouca representatividade da cultura indígena nos currículos, consequentemente, promove a manutenção de livros didáticos nessa mesma perspectiva.

\footnotetext{
${ }^{1}$ Mestra em Ensino de Ciências e Humanidades; licenciada em Ciências: matemática e física, todas as titulações pela Universidade Federal do Amazonas (UFAM). Professora da rede pública no estado do Amazonas. Orcid iD: https://orcid.org/0000-0003-2551-5900.E-mail: mardilabueno@gmail.com

${ }^{2}$ Doutora em Ciências (área de concentração: Ensino de Física) pela Universidade de São Paulo (USP). Professora Adjunta da Universidade Federal do Amazonas no curso de Licenciatura em Ciências: Matemática e Física e no Programa de Pós Graduação em Ensino de Ciências e Humanidades. Orcid iD: https://orcid.org/0000-0002-59220273.E-mail: elrismaroliveira@ufam.edu.br.

${ }^{3}$ Doutoranda e mestra em Ciências (área de concentração: Ensino de Física); licenciada em Física e em História, todas as titulações pela Universidade de São Paulo (USP). Professora da rede pública e privada no estado de São Paulo; colaboradora na produção de coleções didáticas em ciências e física. Orcid iD: https://orcid.org/0000-00032036-4090.E-mail: martasouza@usp.br.

${ }^{4}$ Doutora em Educação pela Pontifícia Universidade Católica de São Paulo (PUC). Professora Adjunta da Universidade Federal do Amazonas no curso de pedagogia e no Programa de Pós graduação em Ensino de Ciências e Humanidades. Orcid iD: https://orcid.org/0000-0002-7725-6464. E-mail: eulinanog@ hotmail.com
}

${ }^{5} \mathrm{O}$ presente trabalho foi realizado com apoio da Universidade Federal do Amazonas (UFAM) e da Coordenação de Aperfeiçoamento de Pessoal de Nível Superior - Brasil (CAPES). 
Palavras-chave: Currículo. Cultura Indígena. Diversidade cultural.

\begin{abstract}
This research aimed to analyze the space occupied by knowledge about indigenous skies in national and state educational documents. The methodology has a qualitative approach. The National Curriculum Parameters, Common National Curricular Base, Curricular Proposals for the State of Amazonas, and National Curriculum Reference for Indigenous Schools were selected for the content analysis. The results show that only the National Curriculum Reference for Indigenous Schools, a specific document for these cultures, presents explicitly elements regarding the knowledge of indigenous skies. The specific approach to indigenous knowledge about the skies in the other documents is small. When it comes to the Curricular Proposals of the State of Amazonas, the lack of these issues is worrying. In the state with the largest number of self-declared indigenous people in the country, addressing issues related to knowledge about indigenous skies would underscore the importance of valuing the knowledge produced by these peoples. The lack of this approach can contribute to naturalize a curriculum that predominantly presents the dominant culture. The little representation of indigenous culture in the curriculum, consequently, promotes the maintenance of textbooks from this same perspective.
\end{abstract}

Keywords: Curriculum. Indigenous culture. Cultural diversity.

\title{
1 Introdução
}

Este artigo é resultado de uma pesquisa de mestrado, na área da astronomia cultural, que buscou compreender o espaço ocupado pelos saberes sobre os céus do povo indígena Parintintin em diferentes âmbitos, envolvendo a análise de documentos escolares, livros didáticos e a realização de entrevistas com membros da aldeia Traíra, da etnia Parintintin ${ }^{6}$. O contexto geral que abarca esses saberes se relaciona, em um primeiro momento, aos conhecimentos tradicionais, que podem ser compreendidos como: "o conjunto de saberes e saber-fazer a respeito do mundo natural, sobrenatural, transmitido oralmente de geração em geração" (DIEGUES, 2000, p. 30). Outra característica fundamental diz respeito à inexistência de uma separação rígida entre o mundo "natural" e o "social", permitindo, por exemplo, que as cosmologias de alguns povos indígenas na Amazônia não façam distinções ontológicas entre humanos, animais, plantas e fenômenos naturais.

O segundo aspecto relacionado diretamente aos saberes sobre os céus diz respeito à variedade de formas de interagir com os objetos e fenômenos celestes, sob a perspectiva de diversas culturas. Assim como os indígenas, cada povo interage e interpreta os fenômenos celestes, de forma singular e de acordo com a sua cultura. "Camponeses, físicos, pintores, poetas, astrônomos, músicos, religiosos, meteorologistas, astrólogos possuem formas singulares de relação com o que conhecemos como céu" (BUENO, 2020, p. 35). Investigar a produção de conhecimentos neste âmbito é o campo de estudo de uma nova área de conhecimento denominada astronomia cultural.

A astronomia cultural não separa fenômenos celestes e terrestres, e por estar diretamente relacionada à cultura de diferentes povos não se limita a uma única interpretação desses fenômenos. Não se trata de uma subárea da astronomia, é uma ciência ligada à antropologia e,

\footnotetext{
${ }^{6} \mathrm{O}$ povo Parintintin vive em três aldeias no município de Humaitá-AM, localizadas nas terras indígenas Nove de Janeiro e Ipixuna, no sul do estado do Amazonas, a saber, as aldeias são: Pupunha, Canavial e Traíra.
} 
portanto, com maior afinidade com a área das ciências humanas. Assim, a astronomia cultural "tem significado tentativas de entendimento e de tradução de como outras culturas, do passado ou do presente, se relacionam com aquilo que no nosso recorte, ocidental, chamamos de céu" (JAFELICE, 2013, p. 1). Essa nova área do conhecimento pode se apresentar com expressões sinônimas como: arqueoastronomia, astroarqueologia, astronomia antropológica e etnoastronomia. Outros autores denominam a etnoastronomia e a arqueoastronomia como subáreas da astronomia cultural.

[e]nquanto a etnoastronomia se ocupa das relações entre o céu e grupos humanos efetivamente existentes, a arqueoastronomia estuda as possíveis relações entre seres humanos de culturas que não estão mais presentes, mas que deixaram evidências concretas de conhecimentos astronômico (CARDOSO, 2016, p. 100).

Por valorizar a diversidade de saberes sobre os céus, a astronomia cultural não hierarquiza saberes e reconhece em igualdade de status o conhecimento tradicional e o científico (BUENO, 2020). Assim, o conhecimento científico "[...] não é visto como especial ou superior, nem implica em alternativa privilegiada (em nenhum sentido, seja social, ontológico, filosófico etc.)" (JAFELICE, 2015, p. 59).

O Brasil, em virtude do processo de colonização, teve sua cultura influenciada pelos indígenas, pelos africanos e pelas matrizes europeias, com destaque para a portuguesa. Porém, devido à colonialidade, que é o que restou das imposições culturais ocorridas pela colonização, muitos dos brasileiros acabam por privilegiar as raízes europeias (BESSA FREIRE, 2010).

Segundo Bessa Freire (2010), um equívoco sobre as culturas indígenas é acreditar que os índios fazem parte do passado. Por volta do ano de 1957, de acordo com dados demográficos da população indígena brasileira da FUNAI (2015), o desaparecimento dos povos indígenas parecia algo evidente. Porém, 20 anos depois, a população indígena voltou a aumentar significativamente ${ }^{7}$ em virtude do movimento indígena, que passa a lutar pela demarcação de terras, por educação e saúde diferenciada. A luta e a resistência dos movimentos indígenas conseguiram garantir na Constituição Federal de 1988 direitos a essas populações, relacionados à preservação da organização social, línguas e tradições, à educação, à saúde e ao território.

O Instituto Socioambiental (ISA) apresenta a estimativa da existência aproximada de 254 diferentes povos indígenas no Brasil. Desse total, 179 populações encontram-se em estados da região norte do país, sendo que 64 delas estão no estado do Amazonas.

Considerando as possibilidades da inserção da astronomia cultural nos currículos e suas contribuições para o processo de ensino-aprendizagem na educação básica brasileira, o objetivo deste trabalho é analisar a presença de saberes sobre os céus indígenas em documentos educacionais brasileiros, inclusive do estado do Amazonas. Compreendemos esses saberes como práticas e conhecimentos produzidos por essas populações no contexto da astronomia cultural.

Selecionamos para análise: Parâmetros Curriculares Nacionais (PCN) (BRASIL, 1998a), Base Nacional Comum Curricular (BNCC) (BRASIL, 2017), Referencial Curricular Nacional para as Escolas Indígenas (RCNE/I) (BRASIL, 1998b) e Propostas Curriculares do Estado do Amazonas (AMAZONAS, [200- $]^{8}$ ). Nosso recorte selecionou documentos que podem apresentar conteúdo das diferentes áreas do conhecimento e, assim, entre eles,

\footnotetext{
${ }^{7}$ Bueno (2020) apresenta dados demográficos da população indígena brasileira do período de 1500 a 2010.

${ }^{8}$ Década certa; o documento não informa o ano.
} 
identificar aqueles que se relacionam à astronomia cultural, especificamente saberes sobre os céus indígenas.

Considerando a maior possibilidade de encontrar temas relacionados ao céu de uma forma geral, em ciências naturais e em geografia do ensino fundamental, escolhemos esses componentes para análise de todos os documentos citados anteriormente. Para a seleção e análise do material que compõe essa pesquisa, utilizamos a Análise de Conteúdo (BARDIN, 2011; MORAES, 1999). A Análise de Conteúdo trata-se de "um conjunto de técnicas de análise das comunicações. [...] um único instrumento, mas marcado por uma grande disparidade de formas e adaptável a um campo de aplicação muito vasto: as comunicações" (BARDIN, 2011, p. 31). A categorização, a descrição e a interpretação são as principais etapas desta metodologia. Para apresentação dos resultados, não elaboramos categorias; as unidades de análise são excertos dos documentos que compõem o texto, procurando mostrar a presença de elementos de saberes sobre os céus indígenas nos documentos curriculares. Antes, porém, apresentamos um breve estudo sobre currículo escolar.

\section{Cultura escolar e currículo}

O ambiente escolar é o espaço onde podemos encontrar a grande diversidade cultural brasileira. A cultura escolar, considerando tanto elementos materiais (carteiras, uniformes, quadro, currículo oficial) como imateriais (normas e comportamentos - formação de fileiras, silêncio, horários), é parte da organização da escola concebida pela sociedade moderna, não indígena. Devemos considerar que muitos indígenas estudam em escolas urbanas e que essa cultura escolar está presente também em escolas indígenas.

Acreditamos que uma das maneiras de contribuir para a prática da interculturalidade crítica, que Walsh (2009) define como um projeto político de decolonização, transformação e criatividade, é a inserção da cultura de minorias nos currículos escolares. Entendemos que somente a inserção desses conteúdos, como determina a Lei $n^{\circ} 11.645 / 2008$, que trata da obrigatoriedade da inclusão da temática "História e Cultura Afro-Brasileira e Indígena" no currículo oficial da rede de ensino, não é suficiente. Apontamos a necessidade de ações, por exemplo, no âmbito da formação inicial e continuada de professores para que se concretizem mudanças curriculares propostas a partir da legislação. Mas, considerando que alguns documentos que regem a educação brasileira são normativos, a obrigatoriedade indicada pela lei pode ser vista como um primeiro passo para o trabalho com aspectos da diversidade cultural que inclui os povos indígenas no Brasil.

Nosso entendimento de currículo corrobora com Forquin (1996) que o divide em: currículo real (ativo), currículo formal (escrito ou prescrito) e currículo oculto. O currículo oculto, segundo o autor, "[...] implica a ideia de alguma coisa implícita ou invisível [...] a própria organização da vida escolar, a estruturação escolar do tempo e do espaço, a codificação e a ritualização das atividades" (FORQUIN, 1996, p. 193).

O Currículo formal, o autor define como aquele prescrito pelas autoridades, composto por documentos normativos e orientativos. Por fim, o currículo real "[...] é aquilo que é realmente ensinado nas salas de aula, que se pode conhecer por observação ou por pesquisa direta com os professores e os alunos [...]" (FORQUIN, 1996, p. 191).

Silva (2011), Candau e Russo (2010) escrevem sobre as relações de poder existentes nos currículos. Segundo Silva (2011), 
O texto curricular, entendido aqui de forma mais ampla - o livro didático e paradidático, as lições orais, as orientações curriculares oficiais, os rituais escolares, as datas festivas e comemorativas - está recheado de narrativas nacionais, étnicas e raciais. Em geral, essas narrativas celebram os mitos de origem nacional, confirmam o privilégio das identidades dominantes e tratam as identidades dominadas como exóticas ou folclóricas. Em termos de representação racial, o texto curricular conserva, de forma evidente, as marcas da herança colonial (SILVA, 2011, p. 101102).

A pesquisa de Bueno (2020) mostra, a partir de entrevista com professores indígenas, subversão aos livros didáticos fornecidos pelo Programa Nacional do Livro e do Material Didático (PNLD), visto que, segundo os docentes, há pouca representatividade da cultura indígena nos mesmos. Esses professores indígenas afirmam que raramente utilizam livros didáticos em suas aulas.

Silva (2011), Candau e Russo (2010) criticam currículos multiculturais que pregam uma simples tolerância pela cultura do outro, visando a mera pacificação de conflitos e evitando discussões sobre a origem das desigualdades sociais. Esses autores defendem um currículo intercultural que não apenas se preocupe com o que ensinar, mas com quais cidadãos queremos formar e fazem uma crítica também ao que o currículo faz ao ter predominantemente a cultura dominante como base dos conteúdos abordados em sala de aula.

Corroborando com Silva (2011), em relação aos textos curriculares, acreditamos que no meio educacional a astronomia cultural, que tem caráter holístico e transdisciplinar, pode contribuir para uma educação humanística, entrelaçando sujeito e objeto, favorecendo a relação ensino-aprendizagem. Além disso, essa perspectiva favorece o reconhecimento e valorização de culturas minoritárias.

\section{Astronomia cultural em documentos educacionais}

A recomendação ou determinação de temáticas que abordem as diferenças culturais está prescrita em documentos oficiais da educação brasileira. A Lei $n^{\circ}$ 9.394/1996, que estabelece as diretrizes e bases da educação nacional, alterada pela Lei ${ }^{\circ}$ 11.645/2008, tornou obrigatório o estudo da história e da cultura afro-brasileira e indígena em todo o currículo escolar.

Os Parâmetros Curriculares Nacionais (BRASIL, 1998a), documentos orientativos, no texto dos Temas Transversais (Ética, Orientação sexual, Trabalho e consumo, Meio ambiente, Saúde, e Pluralidade cultural) afirmam que o trabalho com a pluralidade cultural exige " [...] que a escola alimente uma 'Cultura da Paz', baseada na tolerância, no respeito aos direitos humanos e na noção de cidadania compartilhada por todos os brasileiros" (BRASIL, 1998a, p. 117). Esse excerto vem reiterar a crítica de Candau e Russo (2010) aos currículos multiculturais, mencionada anteriormente, que pregam a tolerância pela cultura do outro.

Diferentemente dos PCN (BRASIL, 1998a), a Base Nacional Comum Curricular (BNCC) (BRASIL, 2018), aprovada no ano de 2018 ${ }^{9}$, é um documento normativo. Ela determina conteúdos mínimos para o ensino das diversas áreas do conhecimento da educação infantil ao ensino médio e também legisla na construção dos documentos das escolas, como, por exemplo, os Projetos Políticos Pedagógicos. A BNCC (BRASIL, 2018) determina dez

\footnotetext{
${ }^{9}$ A BNCC para a etapa do ensino fundamental foi aprovada em 2017 e a do ensino médio, em 2018.
} 
competências gerais que devem permear todas as áreas. A sexta e nona competências tratam das diferenças culturais citando que os educandos devem:

6. Valorizar a diversidade de saberes e vivências culturais e apropriar-se de conhecimentos e experiências que lhe possibilitem entender as relações próprias do mundo do trabalho e fazer escolhas alinhadas ao exercício da cidadania e ao seu projeto de vida, com liberdade, autonomia, consciência crítica e responsabilidade. [...] 9.Exercitar a empatia, o diálogo, a resolução de conflitos e a cooperação, fazendo-se respeitar e promovendo o respeito ao outro e aos direitos humanos, com acolhimento e valorização da diversidade de indivíduos e de grupos sociais, seus saberes, identidades, culturas e potencialidades, sem preconceitos de qualquer natureza (BRASIL, 2018, p. 9-10).

Ainda no contexto da BNCC, ressaltamos a existência de um documento intitulado "Temas Contemporâneos Transversais na BNCC - contexto histórico e pressupostos pedagógicos" (BRASIL, 2019). Nele é reforçada a necessidade de inserção de questões sociais no currículo escolar, partindo da ideia de Temas Transversais, presentes nos PCN (BRASIL, 1998a), e propondo os Temas Contemporâneos Transversais (TCTs), que devem atuar na contextualização do que é ensinado, de maneira atenta às demandas do mundo atual. O caráter transversal dos temas incentiva o trabalho com as mais diferentes áreas do conhecimento. São propostos 15 TCTs, divididos em seis macroáreas temáticas. Considerando nosso interesse de pesquisa, destacamos a macroárea "Multiculturalismo", que apresenta os Temas Contemporâneos Transversais a seguir: "Diversidade cultural" e "Educação para valorização do multiculturalismo nas matrizes históricas e culturais brasileiras". Embora não apresente indicação de conteúdos, na área de ciências, a astronomia cultural permite o trabalho com tais TCTs.

A Proposta Curricular do Estado do Amazonas, que identifica sua construção em consonância com a LDB, com as Diretrizes Curriculares para o Ensino Fundamental e com os PCN (BRASIL, 1998a), também é um documento orientativo e que compreende o "[...] currículo como princípios pedagógicos de identidade, diversidade, autonomia, interdisciplinaridade e contextualização de uma proposta em construção para emancipação social” (AMAZONAS, [200-], p.12).

O Referencial Curricular Nacional para as Escolas Indígenas - RCNE/I (BRASIL, 1998b), é um documento ${ }^{10}$ que compõe os PCN (BRASIL, 1998a). Este documento reconhece a pluralidade de conhecimentos produzidos pelos povos indígenas. Segundo ele, a escola é um dos espaços "onde a relação entre os conhecimentos próprios e os conhecimentos das demais culturas deve se articular [...]” (BRASIL, 1998b, p. 24).

Consideramos que documentos relacionados à educação brasileira reconhecem a diversidade cultural do Brasil e a astronomia cultural como uma das possibilidades de inserção de culturas indígenas nos currículos escolares.

Como já mencionado, selecionamos para análise: PCN (BRASIL, 1998a), BNCC (BRASIL, 2017), RCNE/I (BRASIL, 1998b) e Propostas Curriculares do Estado do Amazonas (AMAZONAS, [200-]), e a partir dos conteúdos de ciências naturais e de geografia do ensino fundamental, procuramos identificar elementos que se relacionem à astronomia cultural, especificamente saberes sobre os céus indígenas. Esses elementos estão apresentados a seguir.

${ }^{10}$ Os RCNE/I se auto intitula com “função formativa e não normativa” (RCNE/Indígena, 1998b, p. 13). 


\subsection{Parâmetros Curriculares Nacionais}

O ensino fundamental, nos PCN (BRASIL, 1998a), está organizado em quatro ciclos. Os dois primeiros ciclos compõem os anos iniciais. No fundamental II, ou anos finais, estão o terceiro $\left(6^{\circ}\right.$ e $7^{\circ}$ ano $)$ e o quarto ciclo $\left(8^{\circ}\right.$ e $9^{\circ}$ ano $)$. Procuramos conteúdos referentes à astronomia cultural nos PCN do ensino Fundamental II (BRASIL, 1998a) de ciências naturais e de geografia.

Os PCN de ciências naturais (BRASIL, 1998a) estabelecem quatro eixos temáticos para o ensino desse componente curricular, sendo eles: "Vida e Ambiente"; "Ser Humano e Saúde"; "Tecnologia e Sociedade"; e "Terra e Universo". Neste último, podemos encontrar temas sobre fenômenos celestes, assim, nossa análise será neste eixo temático.

A análise mostra, no terceiro ciclo, que discussões ou conteúdos recorrentes em astronomia cultural estão presentes. Neles os PCN de ciências naturais (BRASIL, 1998a) procuram fazer conexão entre conhecimentos sobre os céus e elementos do documento Temas Transversais, em que a pluralidade cultural está contemplada.

Conforme o Sol se movimenta em relação ao horizonte, sua luz projeta sombras que também se movimentam, variando em comprimento e direção: de manhã, as sombras são compridas; com o passar das horas, vão se encurtando e, ao meio-dia, são mínimas ou inexistem. Depois disso, vão se encompridando para o lado oposto até o fim da tarde. São observações como essas que permitiram a construção de calendários pelas diferentes culturas, refletindo diferentes concepções de "Terra e Universo", um tema a ser desenvolvido em conexão com Pluralidade Cultural (BRASIL, 1998a, p. 63, grifo nosso).

A construção de um relógio solar é importante atividade para os alunos realizarem, discutindo o tamanho das sombras durante o dia e conhecendo como os povos antigos construíram seus relógios (BRASIL, 1998a, p. 63, grifo nosso).

Os estudantes devem ser orientados para articular informações com dados de observação direta do céu, utilizando as mesmas regularidades que nossos antepassados observaram para orientação no espaço e para medida do tempo, o que foi possível muito antes da bússola, dos relógios e do calendário atual, mas que junto a eles ainda hoje organizam a vida em sociedade em diversas culturas, o que pode ser trabalhado em conexão com o tema transversal Pluralidade Cultural. Dessa forma, os estudantes constroem o conceito de tempo cíclico de dia, mês e ano, enquanto aprendem a se situar na Terra, no Sistema Solar e no Universo (BRASIL, 1998a, p. 40, grifo nosso)

Os excertos mostram que elementos da astronomia cultural nos PCN de ciências naturais (BRASIL, 1998a) não explicitam nenhuma cultura específica. Trazem expressões como "diferentes culturas", "povos antigos", "nossos antepassados", ao tratar de orientação espacial e medidas de tempo.

Ainda no terceiro ciclo, no eixo Terra e Universo, são elencados quatro conteúdos centrais para o desenvolvimento de conceitos, procedimentos e atitudes. Entre eles está: "Valorização dos conhecimentos de povos antigos para explicar os fenômenos celestes" (BRASIL, 1998a, p.67). Nesse sentido, o texto do quarto ciclo apresenta uma breve referência à arqueoastronomia, mencionando o monumento de Stonehenge, no seguinte trecho:

Registrar a observação do céu é algo muito antigo. O monumento de Stonehenge, situado na Inglaterra e construído há cerca de 2500 anos a.C., revela um método sofisticado de calcular o calendário, assinalando solstícios e equinócios com precisão (BRASIL, 1998a, p. 92).

Diferentemente das ciências naturais, a denominação dos eixos temáticos da geografia não é a mesma nos dois ciclos finais. Para o terceiro ciclo são: “A geografia como uma 
possibilidade de leitura e compreensão do mundo"; "O estudo da natureza e sua importância para o homem"; "O campo e a cidade como formações socioespaciais"; e "A cartografia como instrumento na aproximação dos lugares e do mundo". Para o quarto ciclo, são denominados de: A evolução das tecnologias e as novas territorialidades em redes; Um só mundo e muitos cenários geográficos; e Modernização, modo de vida e a problemática ambiental.

Na análise dos PCN de geografia (BRASIL, 1998a) também não encontramos nenhuma menção específica sobre conhecimentos indígenas sobre os céus.

\subsection{Base Nacional Comum Curricular}

O ensino fundamental II está organizado, segundo a BNCC (BRASIL, 2017), em cinco áreas do conhecimento: linguagens; matemática; ciências da natureza; ciências humanas; e ensino religioso. Essas áreas podem abrigar um ou mais componentes curriculares. Além disso, a BNCC (BRASIL, 2017) estabelece competências gerais e específicas, assim como habilidades para cada área. O documento cita que essas "habilidades estão relacionadas a diferentes objetos de conhecimento - aqui entendidos como conteúdos, conceitos e processos -, que, por sua vez, são organizados em unidades temáticas" (BRASIL, 2017, p. 28). A área de ciências da natureza está organizada em três unidades temáticas, a saber: "Matéria e energia"; "Vida e Evolução"; e "Terra e Universo".

$\mathrm{Na}$ análise do documento de ciências da natureza, realizamos a leitura dos objetos de conhecimentos e de suas respectivas habilidades. Encontramos elementos de astronomia cultural apenas no $9^{\circ}$ ano, na unidade temática "Terra e Universo". Esses elementos estão presentes no objeto de conhecimento: "astronomia e cultura". A habilidade EF09CI15, relacionada a este objeto de conhecimento, determina: "Relacionar diferentes leituras do céu e explicações sobre a origem da Terra, do Sol ou do Sistema Solar às necessidades de distintas culturas (agricultura, caça, mito, orientação espacial e temporal etc.) "(BRASIL, 2017, p. 351).

$\mathrm{O}$ excerto anterior mostra que em ciências da natureza a abordagem não se refere aos conhecimentos indígenas sobre os céus especificamente, mas deixa espaço para tratar de diferentes culturas, do passado e do presente, de uma forma pragmática, como podemos observar na citação anterior, relacionando as interpretações do céu às necessidades de cada povo.

A área de geografia na BNCC (BRASIL, 2017) está organizada em cinco unidades temáticas, a saber: "O sujeito e seu lugar no mundo"; "Conexões e escalas"; "Mundo do trabalho"; "Formas de representação e pensamento espacial"; e "Natureza, ambientes e qualidade de vida". Nesse documento, da mesma forma que nos PCN (BRASIL, 1998a), não encontramos elementos da astronomia cultural no componente curricular geografia.

\subsection{Proposta Curricular do Ensino Fundamental da rede pública do estado do Amazonas}

Procuramos mapear a astronomia cultural também na Proposta Curricular do Ensino Fundamental do $6^{\circ}$ ao $9^{\circ}$ ano da rede pública do estado do Amazonas. As propostas curriculares para cada componente são divididas em objetivos gerais; objetivos específicos; conteúdos; conceitos; procedimentos e atitudes.

A Proposta Curricular do Ensino Fundamental do $6^{\circ}$ ao $9^{\circ}$ ano da rede pública do estado do Amazonas da disciplina de ciências naturais possui como eixo temático no ensino fundamental II: O homem, sua história e evolução. Ela inclui o ensino de física, química, 
geociências e astronomia. Não encontramos temas referentes à astronomia cultural nesse documento.

Já a Proposta Curricular do Ensino Fundamental do $6^{\circ}$ ao $9^{\circ}$ ano da rede pública do estado do Amazonas da disciplina de geografia, cujo eixo temático para o fundamental II é: A Terra como morada, espaço, natureza e cultura, apresenta temas de astronomia cultural no $6^{\circ}$ ano, como podemos observar no Quadro 1 a seguir:

Quadro 1 - Excertos de astronomia cultural na proposta curricular da disciplina de geografia do estado do Amazonas.

\begin{tabular}{|c|l|l|}
\hline \multicolumn{1}{|c|}{ Conceito } & \multicolumn{1}{|c|}{ Procedimento } & \multicolumn{1}{c|}{ Atitude } \\
\hline $\begin{array}{l}\text { Compreender a origem do universo: } \\
\text { sem }^{11} \begin{array}{l}\text { movimentos } \\
\text { transformações. }\end{array}\end{array}$ & $\begin{array}{l}\text { eralhar atividades que explorem o } \\
\text { contexto geográfico da sociedade } \\
\text { local e global. }\end{array}$ & $\begin{array}{l}\text { Interpretar diferentes visões de } \\
\text { mundo, tanto no contexto local } \\
\text { quanto no global. }\end{array}$ \\
\hline \multicolumn{2}{|c|}{ Fonte: Bueno (2020, p. 67, grifo nosso) }
\end{tabular}

O Quadro 1 é composto por conceitos, procedimentos e atitudes que, segundo a proposta curricular, estão baseados nas metas, diretrizes, objetivos gerais e específicos para o ensino fundamental, bem como nos Parâmetros Curriculares Nacionais.

Acreditamos que o conceito descrito no Quadro 1, "Compreender a origem do universo", somado à atitude de "interpretar diferentes visões de mundo", pode encaminhar possibilidades de abordar cosmologias diversas, favorecendo assim atividades educacionais relacionadas à astronomia cultural. Porém, como os outros documentos oficiais que orientam ou legislam a educação regular do Brasil - PCN e BNCC - a Proposta Curricular do Ensino Fundamental do $6^{\circ}$ ao $9^{\circ}$ ano do estado do Amazonas, embora seja o estado com o maior número de indígenas no país, não se refere aos conhecimentos indígenas sobre os céus.

\subsection{Referencial Curricular Nacional para as Escolas Indígenas - RCNE/Indígena}

O RCNE/I (BRASIL, 1998b) do ensino fundamental é dividido em duas partes. A primeira aborda assuntos referentes à diversidade, à educação escolar indígena, aos marcos legais e históricos. A segunda parte, intitulada "Ajudando a construir os currículos escolares", é dedicada a auxiliar a construção de currículos de escolas indígenas, especialmente os Projetos Políticos Pedagógicos (PPP). Dado seu caráter, essa parte do documento é considerada na análise. Nas sugestões de construção dos currículos, o documento integra diversos componentes $^{12}$ (línguas, matemática, geografia, história, ciências, arte e educação física) a seis temas transversais (autossustentação; ética indígena; pluralidade cultural; direitos, lutas e movimentos; terra e preservação da biodiversidade; e educação preventiva para a saúde).

O documento está dividido em nove capítulos e apresenta "princípios mínimos necessários, em cada área de estudo do currículo, para que se possam traduzir os objetivos que se quer alcançar em procedimentos de sala de aula" (BRASIL, 1998b, p. 13). É também nessa segunda parte que o documento apresenta sugestões de conteúdos e atividades a serem trabalhadas em contextos educacionais indígenas. É importante salientar que o documento é

\footnotetext{
${ }^{11}$ Acreditamos ser: Compreender a origem do universo: seus movimentos e transformações.

12 O documento chama os componentes curriculares de áreas de estudo.
} 
referente ao ensino fundamental I e II e possui sugestões de conteúdos e atividades divididos nos diversos componentes curriculares. Além disso, diferentemente dos PCN (BRASIL, 1998a) e da BNCC (BRASIL, 2017), o RCNEI/Indígena (BRASIL, 1998b) não separa as etapas do ensino fundamental em ciclos ou séries específicas. Segundo o documento:

\footnotetext{
Por conter princípios e fundamentos gerais de ensino para as várias áreas de estudo presentes no ensino fundamental, e não orientações programáticas fechadas em uma "grade", este Referencial pode ser pensado e aplicado nas séries ou ciclos iniciais ou finais, dependendo da situação de cada escola em particular (BRASIL, 1998b, p. 06).
}

Uma das particularidades da elaboração desse documento é a participação de professores indígenas. O texto contém falas de educadores de diversas etnias, descrevendo vivências e práticas educacionais já realizadas por eles. Na apresentação dessas experiências aparecem temas de astronomia cultural. Segundo o documento, a interculturalidade pode oportunizar a vivência de práticas interdisciplinares na interação entre os conhecimentos tradicionais e os conhecimentos científicos. Nessas práticas "[...] os alunos das escolas indígenas têm condição de reelaborar (às vezes modificando, às vezes ampliando) seu próprio conhecimento sobre o tema/problema em estudo" (BRASIL, 1998b, p. 61).

O RCNE/I (BRASIL, 1998b) reconhece a diversidade cultural dos povos indígenas e defende a inserção dos conhecimentos étnicos no currículo, trazendo como uma das possibilidades a agregação de conhecimentos dos mais velhos, lideranças indígenas, pais, artesãos, dentre outros, considerando que a educação escolar indígena acontece além do ambiente escolar.

Cada componente curricular é apresentado em uma seção que aborda temas gerais amplos e seus respectivos objetivos didáticos. Os temas, por sua vez, contemplam os conteúdos que são apresentados em forma de questionamentos. Na seção destinada ao componente curricular de geografia e contextos locais, encontramos astronomia cultural nos temas: 1) Os espaços geográficos da aldeia, do território, de outros territórios e 2) Os espaços geográficos brasileiros. Em relação a estes temas, os conteúdos e consequentemente os questionamentos relacionados a eles estão descritos no Quadro 2 a seguir.

Quadro 2 - Excertos de astronomia cultural no componente curricular de geografia e contextos locais do Referencial Curricular Nacional para as Escolas Indígenas

\begin{tabular}{|c|c|l|}
\hline \multicolumn{2}{|c|}{ Componente curricular: geografia e contextos locais } \\
\hline Tema & Conteúdo & \multicolumn{1}{c|}{ Excertos de astronomia cultural } \\
\hline \multirow{2}{*}{\begin{tabular}{|l|l|} 
Como é o céu do lugar onde eu moro? É diferente do de outros \\
lugares? (BRASIL, 1998b, p. 233) \\
Como é a relação que o povo indígena tem com a Terra, com a \\
mata, com os rios, com os animais, com o Sol, com a Lua, com as \\
estrelas? Esta relação será que é diferente da forma como outros \\
povos se relacionam e interagem com a mata, com o campo, com
\end{tabular}} \\
\hline
\end{tabular}




\begin{tabular}{|c|c|c|}
\hline \multirow{2}{*}{$\begin{array}{l}\text { Os espaços geográficos } \\
\text { da aldeia, do território, } \\
\text { de outros territórios }\end{array}$} & \multirow{2}{*}{$\begin{array}{l}\text { Componentes da } \\
\text { natureza e modos } \\
\text { de vida }\end{array}$} & $\begin{array}{l}\text { as águas, com o céu, com os animais? Como é usado o rio? E a a } \\
\text { mata? Existe música para falar de cada coisa dessas? Tem histórias e } \\
\text { mitos sobre o Sol, sobre a Lua? (BRASIL, 1998b, p. 233) }\end{array}$ \\
\hline & & $\begin{array}{l}\text { Como é o clima e as relações de sua cultura com cada tempo? Por } \\
\text { exemplo, depois do tempo das derrubadas e queimadas dos roçados, } \\
\text { os Nambikwara gostam de sair procurando papagaio nos ocos dos } \\
\text { paus, para criar. E o tempo dos papagaios, tempo de fazer longas } \\
\text { viagens a pé, procurando os bichinhos. A comunidade faz algum } \\
\text { ritual para marcar a passagem das estações? Os Krahô, por exemplo, } \\
\text { fazem um ritual quando termina o tempo do verão e começa o do } \\
\text { inverno; nesse ritual, a administração da aldeia passa de uma metade } \\
\text { cerimonial para a outra: a metade verão e a metade Inverno. E em } \\
\text { outros lugares, outros povos, como é o clima? E a passagem das } \\
\text { estações? (BRASIL, 1998b, p. 234) }\end{array}$ \\
\hline $\begin{array}{l}\text { Os espaços geográficos } \\
\text { brasileiros }\end{array}$ & $\begin{array}{l}\text { Identidade, } \\
\text { território e } \\
\text { relações sociais }\end{array}$ & De onde nosso povo surgiu? (BRASIL, 1998b, p. 235) \\
\hline
\end{tabular}

Fonte: Elaborada pelas autoras a partir de Brasil (1998b, grifo nosso).

O Quadro 2 mostra que o RCNE/Indígena (BRASIL, 1998b) apresenta explicitamente elementos de astronomia cultural no componente curricular de geografia e contextos locais indicando a abordagem de saberes sobre os céus indígenas, tais como: observação do céu, mitologias, cosmologias, relações meteorológicas e conhecimento sobre os astros. Chegando a fazer referência a duas etnias: os Nambikwara e os Krahô.

No componente curricular de ciências e saberes indígenas, também encontramos elementos de astronomia cultural, nos seguintes temas: 1) Os seres humanos e o meio ambiente; 2) O corpo humano e a saúde; 3) Atividades produtivas e relações sociais; e 4) A Terra no espaço. As informações encontradas sobre astronomia cultural, na disciplina de ciências e saberes indígenas, estão apresentadas no Quadro 3 a seguir:

Quadro 3 - Excertos de astronomia cultural no componente curricular de ciências e saberes indígenas do Referencial Curricular Nacional para as Escolas Indígenas.

\begin{tabular}{|c|c|c|}
\hline \multicolumn{3}{|c|}{ Componente curricular: ciências e saberes indígenas } \\
\hline Tema & Conteúdo & \multicolumn{1}{c|}{ Excertos de astronomia cultural } \\
\hline $\begin{array}{c}\text { Os seres humanos } \\
\text { e o meio ambiente }\end{array}$ & $\begin{array}{c}\text { Ambientes e suas } \\
\text { transformações }\end{array}$ & $\begin{array}{l}\text { Como são os ambientes aquático, terrestre, celeste? (BRASIL, } \\
1998 \mathrm{~b}, \text { p. 263) }\end{array}$ \\
\hline $\begin{array}{c}\text { O corpo humano e } \\
\text { a saúde }\end{array}$ & $\begin{array}{c}\text { Luz e som, visão e } \\
\text { audição }\end{array}$ & $\begin{array}{l}\text { Você se perguntou alguma vez: por que o Sol é importante? Quais } \\
\text { os benefícios que o Sol pode trazer para o homem? Quais as }\end{array}$ \\
\hline
\end{tabular}




\begin{tabular}{|c|c|c|}
\hline & & $\begin{array}{l}\text { variações das sombras no decorrer do dia e sua relação com as } \\
\text { horas? (BRASIL, 1998b, p. 270) }\end{array}$ \\
\hline $\begin{array}{c}\text { Atividades } \\
\text { produtivas e } \\
\text { relações sociais }\end{array}$ & $\begin{array}{l}\text { Relações econômicas e } \\
\text { ecológicas }\end{array}$ & $\begin{array}{l}\text { Qual a divisão temporal (p. ex. ciclo de um ano dividido em meses } \\
\text { ou ainda divisão em época de chuva e época de seca...) das diversas } \\
\text { atividades, de acordo com a sazonalidade e demarcações anuais } \\
\text { relacionadas com o clima, a cosmologia e outros indicadores } \\
\text { ambientais? (BRASIL, 1998b, p. 274) }\end{array}$ \\
\hline A Terra no espaço & $\begin{array}{l}\text { Explicações sobre o céu } \\
\text { e seus fenômenos; } \\
\text { sistema solar; relação } \\
\text { entre o movimento dos } \\
\text { astros (Sol, Lua, Terra ) } \\
\text { e as medidas de tempo } \\
\text { (dia, ano, fases da lua, } \\
\text { estações do ano) }\end{array}$ & $\begin{array}{l}\text { Você já parou para pensar sobre as coisas que existem no céu e na } \\
\text { terra? O que se vê no céu em noite de Lua cheia? E num dia de sol? } \\
\text { Você saberia responder o que são as estrelas? E o Sol, o que é? Qual } \\
\text { o caminho da Lua pelo céu? Qual o caminho do Sol pelo céu? Qual } \\
\text { o nome das estrelas que você conhece? Como você explica as fases } \\
\text { da Lua? Quais as histórias e mitos sobre o Sol? Quais as histórias e } \\
\text { mitos sobre a Lua e as estrelas? Qual o caminho da Terra pelo céu? } \\
\text { O que é sombra? Quais as variações entre o dia e a noite e nas } \\
\text { estações do ano? Qual o sistema tradicional de medida de tempo } \\
\text { utilizado por seu povo? Quais as histórias e mitos sobre os } \\
\text { eclipses da Lua e do Sol? O que são mapas e globos terrestres? } \\
\text { (BRASIL, 1998b, p. 277) }\end{array}$ \\
\hline
\end{tabular}

Fonte: Elaborada pelas autoras a partir de Brasil (1998b, grifo nosso).

O Quadro 3 mostra elementos da astronomia cultural no componente curricular de ciências e saberes indígenas, tais como: contagem do tempo, cosmologias, relações meteorológicas, dentre outras. Nosso grifo em "A Terra no espaço", mostra alguns desses elementos. Neste tema, são tratados especificamente os saberes sobre os céus. Na parte introdutória da temática, os autores reconhecem a diversidade cultural relacionada ao céu, o caráter holístico dos saberes sobre os céus e a importância de trazer para o ambiente escolar os conhecimentos adquiridos com os mais velhos. Segundo o documento,

Grande parte da mitologia de cada povo está relacionada com o Sol, a Lua, as estrelas e demais corpos celestes. Muitas das ideias e histórias desenvolvidas sobre o homem e a natureza são influenciadas pela concepção que cada povo tem da Terra, de sua relação com os astros (principalmente com o Sol e a Lua) e com sua posição no espaço. Para realizar um bom trabalho em suas aulas de ciências, o professor indígena precisa conhecer as ideias que os mais velhos têm sobre todas essas coisas. $O$ trabalho com seus alunos sobre esse conhecimento será útil não apenas nas aulas dedicadas a este assunto, pois o tipo de concepção do Universo influencia fortemente todas as ideias sobre os demais fenômenos naturais, o comportamento dos animais e do ser humano. As ideias e descobertas da ciência sobre esse tema também são muito importantes para que alunos compreendam um pouco a lógica do pensamento ocidental. Finalmente, a observação do céu, as histórias relacionadas com as estrelas e a compreensão a respeito dos movimentos da Terra, da Lua e do Sol, será uma fonte permanente de prazer e beleza para todos os alunos indígenas (BRASIL, 1998b, p. 276, grifo nosso).

Dois dos quatro objetivos didáticos relacionados à temática citada anteriormente também fazem referência a elementos da astronomia cultural: 1) Conhecer e valorizar as 
explicações de seu povo sobre o céu e seus fenômenos e 2) Conhecer outras explicações sobre o céu e seus fenômenos.

A análise mostra que, dos documentos analisados, somente o RCNE/I (BRASIL, 1998b), documento específico para as culturas indígenas, apresenta explicitamente elementos relacionados a saberes sobre os céus desses povos. Observamos nos documentos analisados a falta de uma abordagem específica de saberes indígenas sobre os céus, podendo contribuir para naturalizar um currículo que apresenta predominantemente a cultura dominante. A pouca representatividade da cultura indígena nos currículos consequentemente promove a manutenção de livros didáticos nessa mesma perspectiva.

Acreditamos que denunciar essa omissão curricular pode alertar e sensibilizar o professor para que ele inclua práticas mais humanísticas em suas aulas, considerando os saberes sobre os céus das culturas indígenas. Como mencionamos, a astronomia cultural é uma área ainda recente no Brasil, com poucos trabalhos nessa temática. Entretanto, ainda que tenhamos um quadro mais restrito em termos de contribuições, autores como Jafelice (2015) discutem a importância da adoção de um viés antropológico na abordagem a temas em astronomia, visando a criação de práticas em astronomia cultural. Nesse sentido, reunimos um conjunto de trabalhos e pesquisas (CARDOSO, 2007; AFONSO, 2006; 2009; AFONSO et al, 2011; FAULHABER, 2004; 2017; JAFELICE, 2015; 2010; FERNANDES, 2010) que podem auxiliar os professores para, a partir delas, incluírem em suas aulas elementos sobre os céus de povos indígenas que vivem no Brasil, conforme será detalhado a seguir.

A pesquisa de Cardoso (2007) está entre as primeiras teses e dissertações produzidas no Brasil, na área de educação, voltada à temática da astronomia cultural (ou etnoastronomia). Trata-se de uma tese de doutorado de caráter etnográfico, intitulada: "O Céu dos Tukano na escola Yupuri: construindo um calendário dinâmico". A pesquisa foi realizada a partir de oficinas na Escola da própria comunidade indígena. Essas oficinas contaram com a participação dos conhecedores tradicionais, com o objetivo de proporcionar aos estudantes da Escola Yupuri estudar e identificar as constelações de seus antepassados. No trabalho, o autor relata que as constelações do povo Tukano orientam a previsão de fenômenos naturais e aspectos espirituais do cotidiano.

Os trabalhos de Afonso (2006; 2009), Afonso et al (2011) e Faulhaber (2004; 2017), abordam relações práticas e espirituais que grupos indígenas realizam com fenômenos e corpos celestes. Já Jafelice (2015; 2010), conforme indicamos brevemente em parágrafos anteriores, apresenta atividades que podem ser realizadas em sala de aula sob uma perspectiva antropológica no trato de assuntos sobre os céus, buscando uma abordagem holística e transdisciplinar. O trabalho de Fernandez (2010) traz práticas pedagógicas em situações escolares reais de abordagem humanística para o ensino de astronomia, entre elas a autora apresenta textos sobre a origem do Universo na perspectiva do povo indígena Desana que vive no noroeste do Amazonas, entre o rio Tiquié e Papuri.

\section{Considerações}

Entre os documentos analisados que encontramos conteúdos relacionados à temática investigada, não identificamos o termo astronomia cultural nem expressões sinônimas (arqueoastronomia, astroarqueologia, astronomia antropológica, astronomia cultural e etnoastronomia). Porém, a análise mostrou que discussões e conteúdos referentes a essa temática estão presentes sem seu devido destaque e, porque não dizer, quase inexistentes em alguns dos currículos oficiais. 
Percebemos, no decorrer da leitura dos documentos educacionais, principalmente nos PCN de ciências (BRASIL, 1998a), uma abordagem significativa de temas da astronomia acadêmica em detrimento à astronomia cultural. Vale destacar que entre todos, os PCN (BRASIL, 1998a) são a coleção de documentos mais antiga. O tema transversal da pluralidade cultural foi um avanço na discussão daquele período, mas na área de ciências sua abordagem é superficial. Tivemos um crescimento da temática só mais recentemente, um indício desse crescimento pode ser a aprovação da Lei no 11.645/2008

Preocupamo-nos, assim como Silva (2000), com o desmerecimento de tais temas. De acordo com o autor, o multiculturalismo e a diferença são tratados "de forma marginal", tornando-se questões isoladas que prezam apenas pelo respeito e pela tolerância da diversidade cultural brasileira.

Jafelice (2016) realizou um levantamento referente à astronomia cultural na BNCC, na época em que o documento estava em construção. Em sua publicação, chama a atenção para a omissão do documento em relação a temática da astronomia cultural. $\mathrm{O}$ autor encontrou "apenas entradas muito genéricas e vagas ou incompletas, ou improcedentes, sobre "o tema", (JAFELICE, 2016, p. 11). Salientamos que, após a oficialização, não houve mudanças na quantidade de conteúdos de astronomia cultural na BNCC. Chamamos assim a atenção para a pouca relevância dada a essa temática, uma vez que a BNCC é um documento normativo, que regula inclusive a elaboração dos livros didáticos.

Outro fator importante a observar é que os temas da astronomia cultural são quase inexistentes ${ }^{13}$ na proposta curricular de geografia do estado do Amazonas e ausentes na proposta de ciências naturais. Considerando que o Amazonas é o estado com o maior número de pessoas autodeclaradas indígenas no país, a abordagem de temas relacionados à astronomia cultural ressaltaria a importância da valorização dos conhecimentos produzidos por esses povos.

Reconhecemos a presença marcante de temas relacionados à astronomia cultural no RCNE/I (BRASIL, 1998b) de forma que valoriza e compreende a importância dos etnoconhecimentos dos povos indígenas. Esse documento, como mencionamos, chega a mencionar elementos de astronomia cultural citando duas etnias.

Por outro lado, ressaltamos que os conhecimentos tradicionais devem ser valorizados tanto quanto os científicos e não devem ficar limitados apenas à educação escolar indígena. Por isso, defendemos a necessidade de um maior espaço aos conteúdos de astronomia cultural nos documentos oficiais que permeiam toda a educação brasileira tanto quanto dado aos científicos.

\section{Agradecimentos}

Agradecemos à Fundação de Amparo à Pesquisa do Estado do Amazonas (FAPEAM) pela concessão da bolsa de estudos.

\footnotetext{
13 Encontramos na proposta de geografia apenas um conceito relacionado a cosmologia (Compreender a origem do universo: seus movimentos e transformações). A atitude referente a esse conceito dá margem a inserção da astronomia cultural: Interpretar diferentes visões de mundo, tanto no contexto local quanto no global.
} 


\section{Referências}

AFONSO, Germano Bruno. Mitos e Estações no céu Tupi-Guarani. Scientific American Brasil. 45 ed., pp. 46-55, 2006. Disponível em:

http://www2.uol.com.br/sciam/reportagens/mitos_e_estacoes_no_ceu_tupi-guarani_10.html. Acesso em: 5 mar. 2018.

AFONSO, Germano Bruno. Astronomia Indígena. Anais da 61ª Reunião Anual da SBPC Manaus, AM, 2009. Disponível em:

<http://www.sbpcnet.org.br/livro/61ra/conferencias/CO_GermanoAfonso.pdf >. Acesso em: 25 set. 2018.

AFONSO, Germano Bruno et al. A Constelação do Escorpião na Mitologia Indígena. Revista Ciência Hoje, v. 47, pp. 40-45, 2011. Disponível em:

<http://pindorama.art.br/file/16745escorpiao.pdf>. Acesso em: 10 ag. 2018.

AMAZONAS. Proposta Curricular do Ensino Fundamental do $6^{\circ}$ ao $9^{\circ}$ ano. Amazonas: [200-].

BARDIN, Laurence. Análise de Conteúdo. São Paulo: Grupo Almedina, 2011. 279 p.

BESSA FREIRE, José Ribamar. A herança cultural indígena ou cinco ideias equivocadas sobre os índios. In: ARAÚJO, Ana Carvalho Ziller de; CARVALHO, Ernesto Ignácio de; CARELLI, Vicent Robert (org.). Cineastas indígenas: um outro olhar: Guia para professores. Olinda, PE: Vídeo nas Aldeias, 2010, p. 17-33. Disponível em: http://www.videonasaldeias.org.br/downloads/vna_guia_prof.pdf. Acesso em: 31 ag. 2020.

BRASIL. Ministério da Educação. Base Nacional Curricular Comum. Disponível em: http://basenacionalcomum.mec.gov.br/images/BNCC_EI_EF_110518_versaofinal_site.pdf. Acesso em: 04 mar. 2020.

BRASIL, Ministério da Educação. Temas Contemporâneos Transversais na BNCC: contexto histórico e pressupostos pedagógicos. Disponível em:

$<\mathrm{http}$ ///basenacionalcomum.mec.gov.br/images/implementacao/contextualizacao_temas_cont emporaneos.pdf>. Acesso em: 30 ag. 2020.

BRASIL. Ministério da Educação. Lei 11.645, de 10 de março de 2008. Diário Oficial da União: Seção 1, Brasília, DF, p. 1, 12 de março de 2008. Disponível em:

<http://www.planalto.gov.br/ccivil_03/_ato2007-2010/2008/lei/111645.htm>. Acesso em: 10 ag. 2017.

BRASIL. Ministério da Educação. Lei de diretrizes e bases da educação nacional. Brasília: Senado Federal, Coordenação de Edições Técnicas, 1996. Disponível em:

http://www.planalto.gov.br/ccivil_03/LEIS/L9394.htm. Acesso em: 24 nov. 2018.

BRASIL. Ministério da Educação. Parâmetros Curriculares Nacionais: terceiro e quarto ciclo. Brasília: MEC/SEF, 1998a.

BRASIL. Ministério da Educação. Referencial Curricular Nacional para as Escolas Indígenas. Brasília, MEC/SEF, 1998 b. 
BUENO, Márdila Alves. O povo Parintintin e seus saberes sobre o céu: as perspectivas dos conhecedores tradicionais e dos educadores. 2020. 137f. Dissertação (Mestrado) - Curso de Programa de Pós-graduação em Ensino de Ciências e Humanidades, Universidade Federal do Amazonas, Humaitá - AM, 2020.

CANDAU, Vera Maria Ferrão; RUSSO, Kelly. Interculturalidade e educação na América Latina: uma construção plural, original e complexa. Diálogo Educacional, Curitiba, v. 10, n. 29, pp. 151-169, abr. 2010.

CARDOSO, Walmir Thomazi. Astronomia Cultural: como povos diferentes olham o Céu. Eboletim de Física, Brasília, v. 5, n. 5, pp.1-8, out. 2016. Disponível em:

http://periodicos.unb.br/index.php/e-bfis/article/view/21372/15314. Acesso em: 6 maio 2018.

CARDOSO, Walmir Thomazi. O céu dos Tukano na escola Yupuri: construindo um calendário dinâmico. 2007. 390 f. Tese (Doutorado) - Curso de Educação Matemática, Pontifícia Universidade Católica de São Paulo, São Paulo, 2007. Disponível em:

$<$ http://eacultural.fcaglp.unlp.edu.ar/base/Walmir\%20Cardoso/TeseWalmir\%20Thomazi\%20 Cardoso.pdf >. Acesso em: 5 out. 2018.

DIEGUES, Antônio Carlos (org.). Os saberes tradicionais e a biodiversidade no Brasil. Brasília, DF: Ministério do Meio Ambiente; São Paulo: USP, 2000. 211p. Disponível em:https://www.mma.gov.br/estruturas/chm/_arquivos/saberes.pdf. Acesso em: 8 out. 2020.

FAULHABER, Priscila. "As estrelas eram terrenas": antropologia do clima, da iconografia e das constelações Ticuna. Revista de Antropologia, São Paulo, v. 47, n. 2, pp. 379-426, 2004. https://doi.org/10.1590/S0034-77012004000200002. Acesso em: 5 out. 2018.

FAULHABER, Priscila. Leitura interpretativa sobre relações céu-terra entre os índios Tikuna. Revista Anthropológicas, v. 21, pp. 73-104, 2017. Disponível em:

https://periodicos.ufpe.br/revistas/revistaanthropologicas/article/view/231439. Acesso em: 6 maio 2018.

FERNANDES, Gilvana Benevides Costa. Uma abordagem humanística para o ensino de astronomia no nível médio. In: JAFELICE, L. C. (org.). Astronomia, Educação e Cultura: abordagens transdisciplinares para os vários níveis de ensino. Natal: Editora da UFRN, 2010. pp. 89-142.

FORQUIN, Jean Claude. As abordagens sociológicas do currículo: orientações teóricas e perspectivas de pesquisa. Educação e Realidade, Porto Alegre, v. 21, n. 1, pp.187-198, 1996.

FUNAI. Índios do Brasil: Quem são. Brasília: DF, 2015. Disponível em:

<http://www.funai.gov.br/index.php/indios-no-brasil/quem-sao>. Acesso em: 2 fev. 2020.

IBGE. Os indígenas no Censo Demográfico 2010: primeiras considerações com base no quesito cor ou raça. Rio de Janeiro, 2012. 31 p. Disponível em:

$<$ https://indigenas.ibge.gov.br/images/indigenas/estudos/indigena_censo2010.pdf>. Acesso em: 8 maio 2018.

ISA. Instituto Socioambiental. 2018. Disponível em:

https://pib.socioambiental.org/pt/Povo:Parintintim. Acesso em: 5 jul. 2018. 
JAFELICE, Luiz Carlos. Abordagem Antropológica: educação ambiental e astronômica desde uma perspectiva intercultural. In: JAFELICE, L. C. (org.). Astronomia, Educação e Cultura: abordagens transdisciplinares para os vários níveis de ensino. Natal: Editora da UFRN, 2010. pp. 213-426.

JAFELICE, Luiz Carlos. Astronomia cultural nos ensinos fundamental e médio. Revista Latino-americana de Educação em Astronomia, São Carlos, v. 3, n. 19, pp. 57-92, 21 jul. 2015. Semestral. Disponível em: http://www.relea.ufscar.br/index.php/relea/article/view/209. Acesso em: 10 ago. 2017.

JAFELICE, Luiz Carlos. O ensino de astronomia cultural: por quem, para quem, como e para quê? In: IV Simpósio Nacional de Educação em astronomia. 2016, Goiânia. Mesa redonda. Goiânia: Snea, 2016. pp.1-15.

JAFELICE, Luiz Carlos. (coord). Encontro de pesquisa: a Astronomia cultural. II SIMPÓSIO NACIONAL DE EDUCAÇÃO EM ASTRONOMIA, 2012, São Paulo. Atas..., São Paulo: IFUSP, 2013. Disponível em: <http://snea2012.vitis.uspnet.usp.br/sites/de fault/files/SNEA2012_EP_A_Astronomia\%20Cultural.pdf>. Acesso em 23 out. 2018.

MORAES, Roque. Análise de conteúdo. Revista Educação, Porto Alegre, v. 22, n. 37, pp. 732, 1999.

SILVA, Tomaz Tadeu da. A produção social da identidade e da diferença. In: SILVA, Tomaz Tadeu da (org.). Identidade e diferença. Rio de Janeiro: Vozes, 2000. Cap. 2. pp. 73-102.

SILVA, Tomaz Tadeu da. Documentos de Identidade: uma introdução às teorias do currículo. 3. ed. 3. reimp. Belo Horizonte: Autêntica, 2011. 156p.

WALSH, Catherine. Interculturalidad, estado, sociedad: Luchas (De)Coloniales de nuestra época. 1.ed. Quito: Universidad Andina Simón Bolívar, 2009.

Recebido em agosto de 2020.

Aprovado em novembro de 2020. 